Jurnal Sulolipu : Media Komunikasi Sivitas Akademika dan Masyarakat

Vol. 21 No.2 2021

e-issn : 2622-6960, p-issn : 0854-624X

\title{
UJI KEMAMPUAN DAUN TEH HIJAU (CAMELLIA SINENSIS) DALAM MEMATIKAN NYAMUK AEDES AEGYPTI DENGAN MENGGUNAKAN ELEKTRIK ALAT HIT (STUDI EKSPERIMEN)
}

Test the Ability of Green Tea Leaves (Camellia Sinensis) In Killing Aedes Aegypti Mosquitoes By Using An Electric Hit Tool (Experimental Study)

Nurismi Maulana, Zaenab

Jurusan Kesehatan Lingkungan Poltekkes Kemenkes Makassar

Nurismimaulana127@gmail.com

\begin{abstract}
The number of cases of dengue fever has increased drastically in the last few years. The Aedes aegypti mosquito is the type of mosquito that causes dengue fever. Mosquito control that is often carried out is by using chemical insecticides, the use of chemical insecticides will cause Aedes aegypti mosquito resistance, and can have an effect on health and is not environmentally friendly. Green tea leaf extract contains the active ingredients of polyphenols, flavonoids, tannins, saponins and alkaloids. This study aims to find out the ability of green tea leaf extract in killing Aedes aegypti mosquitoes with a variety of concentrations of $60 \%, 80 \%$ and $100 \%$. The research method used is an experimental method with an electric method (hit device) with various concentrations, namely concentrations of $60 \%, 80 \%$ and $100 \%$ and the control is exposed to 25 Aedes aegypti mosquitoes at each concentration, for 2 hours with intervals every 15 minutes. minutes (015 minutes, $15-30$ minutes, 30-45 minutes, 45-60 minutes, 60-75 minutes, 75-90 minutes, 90-105 minutes, and 105-120 minutes), replicated 3 times. The results showed the average death of Aedes aegypti mosquitoes at a concentration of $60 \%$ as much as 18 heads (72\%), concentration of $80 \%$ as much as 22 heads (88\%) and a concentration of $100 \%$ as much as 25 heads (100\%). Based on the research conducted the most effective concentration is $100 \%$. It can be concluded that the results of the study prove green tea leaf extract is able to meet $L^{50}$ in deadly Aedes aegypti mosquitoes. The benefits that can be applied to this study is that people can use green tea leaf extract in shutting down the Aedes aegypti mosquito.
\end{abstract}

Keywords: Green tea leaf extract (camelia sinensi); Aedes aegypti mosquito

\section{ABSTRAK}

Angka kasus kejadian penyakit DBD mengalami peningkatan secara drastis dalam waktu beberapa tahun terakhir Nyamuk Aedes aegypti adalah jenis nyamuk penyebab penyakit DBD. Pengendalian nyamuk yang sering dilakukan yaitu dengan menggunakan insektisida kimiawi, penggunaan instektisida kimiawi akan menimbulkan resistensi nyamuk Aedes aegypti, dan dapat menimbulkan efek bagi kesehatan serta tidak ramah lingkungan berbeda jika menggunakan insektisida alami, tentunya lebih ramah lingkungan dan aman bagi kesehatan. Salah satu instektisida alami yaitu ekstrak daun teh hijau mengandung bahan aktif polifenol, flavonoid, tanin, saponin dan Alkaloid. Penelitian ini bertujuan untuk mengetahui kemampuan ekstrak daun teh hijau dalam mematikan nyamuk Aedes aegypti dengan berbagai variasi konsentrasi yaitu $60 \%, 80 \%$ dan $100 \%$. Metode penelitian yang digunakan bersifat eksperimen dengan metode elektrik (alat hit) dengan berbagai variasi konsentrasi yaitu konsentrasi $60 \%, 80 \%$ dan $100 \%$ dan kontrol yang dipaparkan pada 25 ekor nyamuk Aedes aegypti pada setiap konsentrasi,selama 2 jam dengan interval setiap 15 menit (0-15 menit, 15-30 menit, 30-45 menit, 45-60 menit, 60-75 menit, 75-90 menit, 90-105 menit, dan 105-120 menit), replikasi sebanyak 3 kali. Hasil penelitian menunjukan rata-rata kematian nyamuk Aedes aegypti pada konsentrasi $60 \%$ sebanyak 18 ekor (72\%), konsentrasi $80 \%$ sebanyak 22 ekor (88\%) dan konsentrasi 100\% sebanyak 25 ekor (100\%). Berdasarkan penelitian yang dilakukan konsentrasi yang paling efektif adalah 100\%. Dapat disimpulkan bahwa hasil penelitian membuktikan ekstrak daun teh hijau mampu memenuhi LC ${ }^{50}$ dalam mematikan nyamuk Aedes aegypti. Adapun manfaat yang bisa diterapkan pada penelitian ini yaitu masyarakat dapat menggunakan ekstrak daun teh hijau dalam mematikan nyamuk Aedes aegypti.

Kata kunci : Ekstrak daun teh hijau (camelia sinensis);Nyamuk Aedes aegypti

\section{PENDAHULUAN}

Demam berdarah dengue atau sering dikenal dengan DBD merupakan salah satu jenis penyakit menular yang berbahaya yang menimbulkan kematian dalam waktu singkat dan sering menimbulkan wabah.

Angka kasus kejadian penyakit demam berdarah dengue mengalami peningkatan secara drastis dalam waktu beberapa tahun terakhir. Penyebaran kasus DBD ini hampir menyebar di seluruh dunia. Lebih dari 2,5 milyar penduduk dunia $40 \%$ nya mengalami resiko DBD (Sukohar, 2014).

Dengan adanya masalah-masalah tersebut maka perlu alternatif lain untuk mengendalikan nyamuk Aedes aegypti dengan menggunakan insektisida yang berasal dari alami, tentunya lebih ramah lingkungan dan aman bagi kesehatan. Jenis tanaman insektisida yang akan digunakan sebagai pengganti bahan zat kimia untuk anti nyamuk elektrik. Tanaman-tanaman yang mengandung senyawa aktif saponin, sianida, flavoniod, tanin, alkaloid dan terpenoid (Aseptianova et al, 2017).

Salah satu tanaman dapat di jadikan insektisida alami adalah teh hijau (Camellia sinesis) merupakan tanaman herbal yang banyak dibudidayakan sebagai bahan tradisional (herbal medicine). Hal ini disebabkan karena teh hijau mengandung flavonoid dalam jumlah yang tinggi presentase flavonoid pada daun teh hijau sebanyak $30-40 \%$. Komposisi bahan aktif dalam daun teh hijau adalah kafein, tanin, theophylline, theobromine, lemak, saponin, minyak atsir, karoten, vitamin $\mathrm{C}, \mathrm{A}, \mathrm{BI}, \mathrm{p}$, fluorite, ferum, magnesium, kalsium, 
Jurnal Sulolipu : Media Komunikasi Sivitas Akademika dan Masyarakat

Vol. 21 No.2 2021

e-issn : 2622-6960, p-issn : 0854-624X

strontium, plumbum, nikel, zink dan phosphor. Kandungan tanin pada daun teh akan semakin meningkat seiring dengan peningkatan usia tanaman. Beberapa Kandungan-kandungan tersebut dapat bersifat toksik bagi serangga dan memiliki potensi sebagai insektisida alami (Amelinda et al, 2018).

Peneliti akan melakukan penelitian tentang uji Kemampuan Daun teh (Camellia sinensis) dalam mematikan nyamuk Aedes aegypti menggunakan elektrik (alat Hit) dengan berbagai variasi konsentrasi ekstrak daun teh hijau (Camellia Sinensis) yang dipaparkan pada nyamuk Aedes aegypti sebanyak 25 ekor selama 2 jam dengan interval setiap 15 menit (0-15 menit, 15-30 menit, 30-45 menit, 45-60 menit, 60-75 menit, 75-90 menit, 90-105 menit, dan 105-120 menit).

\section{METODE}

Penelitian ini bersifat eksperimen untuk mengetahui kemampuan ekstrak daun teh hijau (Camellia sinensis) dengan berbagai variasi konsentrasi dalam mematikan nyamuk Aedes aegypti dengan menggunakan metode elektrik (Alat hit).

Lokasi pengambilan sampel daun teh (Camellia sinensis) adalah PT. Malino Highlands.. Adapun Pelaksanaan penelitian di lakukan di laboratorium Jurusan Kesehatan Lingkungan Poltekkes Kemenkes Makassar.

Tahap Penelitian dibagi menjadi dua tahap, yaitu :

a. Tahap persiapan, meliputi penyusunan proposal berlangsung pada Desember 2020 sampai Januari 2021, dan uji pendahuluan pada dilaksanakan pada 4 Januari 2021

b. Tahap penelitian, dilaksanakan pada berlangsung di bulan April - juni 2021.

\section{Alat Dan Bahan}

Adapun alat yang digunakan yaitu: Toples, Ember/Baskom, Saringan, Gelas ukur,Pisau, Gunting, Kurungan nyamuk, Hit, Alat Evaporator/ Kipas, Timbangan, Batang pengaduk, Balok + kain kasa. Adapun bahan yang digunakan yaitu : Daun teh hijau, Methanol, Akuades, Air bersih

\section{Pengumpulan Data}

a. Data Primer

Data primer merupakan data yang didapatkan berdasarkan hasil uji pengamatan yang dilakukan selama penelitian berlangsung dilapangan.

b. Data Sekunder
Data sekunder merupakan data yang diperoleh dari berbagai referensi, baik artikel-artikel, buku, jurnal dan literatur-literatur lain yang diperoleh dari internet yang mendukung dalam pelaksanaan penelitian.

\section{Pelaksanaan Eskperimen}

1. Prosedur Kerja Pembuatan ekstrak

a. Siapkan semua alat dan bahan yang akan digunakan.

b. Daun teh dicuci dengan menggunakan air bersih yang mengalir.

c. Daun teh dikeringkan dengan menggunakan koran.

d. Setelah kering daun teh dipotongpotong dan di timbang sebanyak 500 gram.

e. Kemudian dimasukkan kedalam toples dan diberi label (nama peneliti, tanggal pembuatan dan bahan yang digunakan).

f. Ditambahkan methanol sebanyak 2 liter.

g. Disimpan ditempat yang terhindar dari matahari selama 5 hari dan sesekali daun teh di aduk dengan batang pengaduk.

h. Setelah 5 hari larutan disaring dan disimpan di toples kedua. Sisa daun teh selanjutnya ditambahkan kembali dengan Methanol sebanyak 2 liter.

i. Simpan ditempat yang terhindar dari matahari.

j. Larutan daun teh disaring kemudian di uapkan untuk menghilangkan methanol pada hasil ekstrak tersebut. (Armayanti,2019)

2. Cara membuat konsentrasi ekstrak

a. $100 \mathrm{ml}$ ekstrak daun teh hijau (Camellia sinensis) dengan konsentrasi $60 \%$

$\mathrm{Q}=\frac{\mathrm{S} \cdot \mathrm{A}}{\mathrm{C}}$

$Q=\frac{60 \cdot 100}{100}$

$\mathrm{Q}=60 \mathrm{ml}$

Jadi untuk menghasilkan $100 \mathrm{ml}$ ekstrak daun teh hijau dengan konsentrasi $60 \%$ maka ekstrak daun teh hijau sebanyak $60 \mathrm{ml}$ dan ditambah $40 \mathrm{ml}$ akuades.

b. $100 \mathrm{ml}$ ekstrak daun teh hijau (Camellia sinensis) dengan konsentrasi $80 \%$

$$
\begin{aligned}
& Q=\frac{S . A}{C} \\
& Q=\frac{80.100}{100} \\
& Q=80 \mathrm{ml}
\end{aligned}
$$


Jadi untuk menghasilkan $100 \mathrm{ml}$ ekstrak daun teh hijau dengan konsentrasi $80 \%$ maka ekstrak daun teh hijau sebanyak $80 \mathrm{ml}$ dan ditambah $20 \mathrm{ml}$ akuades.

c. $100 \mathrm{ml}$ ekstrak daun teh hijau (Camellia sinensis) dengan konsentrasi $100 \%$

$\mathrm{Q}=\frac{\mathrm{S} \cdot \mathrm{A}}{100}$

$Q=\frac{100 \cdot 100}{100}$

$\mathrm{Q}=100 \mathrm{ml}$

Jadi untuk menghasikan $100 \mathrm{ml}$ ekstrak daun teh hijau dengan konsentrasi $100 \%$ maka ekstrak daun teh hijau sebanyak $100 \mathrm{ml}$ dan tidak ada penambahan akuades.

Ket :S= Konsetrasi untuk aplikasi (\%)

$\mathrm{C}=$ Konsentasi awal insektisida

$\mathrm{A}=$ Banyaknya larutan yang ingin digunakan (ml)

\section{Prosedur Pelaksanaan}

Siapkan alat dan bahan yang akan digunakan. Kurungan nyamuk yang dijadikan pada penelitian ini ialah balok kecil sebagai rangka, dan menggunakan kain kasa sebagai dinding dengan luas $1 \mathrm{~m} \times 1 \mathrm{~m}$. Untuk sampel nyamuk diperolah dari yang hasil perkembangbiakan dengan membuat perangkap jentik menggunakan ovitrap kemudian dikembangbiakan pada wadah yang telah dirancang hingga menjadi nyamuk dewasa.

\section{Pengolahan Data Dan Analisa Data}

Data pada penelitian ini diperoleh dari hasil pengamatan secara langsung (data primer) yang disajikan dalam bentuk tabel kemudian dianalisa secara deskriptif. Data diolah secara manual dengan menggunakan alat hitung (kalkulator).

\section{HASIL}

Berdasarkan tabel 4 gabungan hasil pemaparan pada konsentrasi $60 \%, 80 \%$ $100 \%$ dan control dengan percobaan I,II dan III, yang dipaparkan selama 120 menit dengan interval setiap 15 menit. Dapat dilihat bahwa pada konsentrasi $60 \%$ kematian nyamuk mencapai 18 ekor (72\%) kemudian pada konsentrasi $80 \%$ kematian nyamuk mencapai 22 ekor (88\%) dan pada konsentrasi $100 \%$ kematian nyamuk mencapai 25 ekor (100\%). Kemudian pada kontrol tidak ada nyamuk yang mati. Dari data tersebut dapat diketahui bahwa semakin tinggi konsentrasi maka tingkat kematian nyamuk lebih tinggi.

\section{PEMBAHASAN}

Nyamuk Aedes aegypti merupakan jenis nyamuk yang membawa virus dangue penyebab penyakit DBD. Kasus DBD semakin tahun semakin meningkat oleh karena itu perlu dilakukan pengendalian untuk menurunkan angka kejadian kasus DBD. pengendalian nyamuk yang sering dilakukan yaitu dengan menggunakan insektisida kimiawi yang memberikan efek menguntungkan sekaligus merugikan. Insektisida yang digunakan secara tepat sasaran, tepat dosis,tepat waktu dan cakupan akan mampu mengendalikan nyamuk Aedes aegypti namun penggunaan instektisida kimiawi akan menimbulkan dampak merugikan dalam jangka waktu tertentu menimbulkan resistensi nyamuk Aedes aegypti, dan dapat menimbulkan efek bagi kesehatan serta tidak ramah lingkungan berbeda jika menggunakan insektisida alami. Insektisida alami berasal dari tanaman yang mengandung senyawa aktif saponin, sianida, flavoniod, tanin, alkaloid dan terpenoid (Aseptianova et al, 2017), hal tersebut mengakibatkan serangga tidak mudah menjadi resisten karena terdapat beberapa senyawa yang berbeda yang terkandung dalam insektisida tersebut. Penggunaan insektisida alami akan memberikan dampak yang positif terhadap pelestarian lingkungan karena bahan yang digunakan mudah terdegradasi sehingga bersifat ramah lingkungan.

Dalam penelitian ini peneliti menggunakan insektisida alami yaitu ekstrak daun teh hijau yang mengandung flavonoid dalam jumlah yang tinggi presentase flavonoid, kafein, tanin, theophylline, theobromine, lemak, saponin, minyak atsir, karoten, vitamin $\mathrm{C}, \mathrm{A}, \mathrm{Bl}, \mathrm{p}$, fluorite, ferum, magnesium, kalsium, strontium, plumbum, nikel, zink dan phosphor (Amelinda et al, 2018).

Adapun tujuan dari penelitian ini yaitu untuk mengetahui tingkat kemampuan ekstrak daun teh hijau dalam mematikan nyamuk Aedes aegypti dengan tiga variasi konsentrasi yaitu $60 \%, 80 \%$ dan $100 \%$ dan kontrol selama 120 menit dengan interval waktu setiap 15 menit, maka diperoleh hasil :

Pada konsentrasi $60 \%$, Diperoleh rata-rata kematian yaitu pada 15 menit dan 
Jurnal Sulolipu : Media Komunikasi Sivitas Akademika dan Masyarakat

Vol. 21 No.2 2021

e-issn : 2622-6960, p-issn : 0854-624X

30 menit belum ada nyamuk yang mati, disebabkan karena waktu pemaparan yang relatif singkat sehingga nyamuk tidak mengalami kematian. Namun, nyamuk hanya menepi ke dinding kurungan akibat dari efek penguapan aroma ekstrak daun teh hijau. Setelah 45 menit diperoleh kematian nyamuk sebanyak 2 ekor (8\%) disebabkan karena nyamuk mulai menghirup aroma senyawa aktif ekstrak daun teh hijau, senyawa aktif tersebut mulai bekerja merusak tubuh nyamuk sehingga nyamuk mati. Kemudian pada 60 menit diperoleh kematian nyamuk sebanyak 2 ekor (8\%), disebabkan karena nyamuk yang banyak menghirup aroma ekstrak daun teh hijau akan mati. selanjutnya pada 75 menit diperoleh kematian nyamuk meningkat sebanyak 3 ekor (12\%) hal ini disebakan karena waktu pemaparan yang lama sehingga kematian nyamuk meningkat. Pada pemaparan 90 menit menjadi 3 ekor $(12 \%)$ dikarenakan uapan dari senyawa aktif yang menyengat dan waktu terpaparnya nyamuk yang lama sehingga kekebalan tubuh nyamuk menurun dan mengakibatkan kematian, kemudian pada 105 menit bertambah menjadi 4 ekor (16\%) hal ini disebabkan karena waktu terpaparnya nyamuk dengan aroma senyawa aktif yang lama sehingga kematian nyamuk semakin meningkat dan pada 120 menit diperoleh kematian nyamuk sebanyak 4 ekor (18\%) disebakan karena senyawa aktif yang berbau menyengat yang terhirup oleh nyamuk dan terpapar sehingga masuk dan merusak tubuh nyamuk sehingga nyamuk mengalami kematian. Kematian nyamuk dapat diketahui pada saat kurungan digerakkan, nyamuk dalam keadaan tidak mampu bergerak, kondisi tersebut,tetap sama setelah alat hit di keluarkan dari dalam kurungan. Dari hasil pemaparan replikasi I, II dan III selama 120 menit pada konsentrasi $60 \%$ kematian ratarata nyamuk Aedes aegypti sebanyak 18 ekor $(72 \%)$.

Dapat disimpulkan bahwa Lethal Consentration 50 (LC_50) telah tercapai artinya ekstrak daun teh hijau pada konsentrasi $60 \%$ mampu mematikan nyamuk Aedes aegypti karena telah memenuhi kriteria (LC_50) dimana kematian nyamuk melebihi $50 \%$ yaitu sebanyak $72 \%$. Hal ini menujukkan bahwa pada saat melakukan pemaparan didalam kotak percobaan terdapat aroma dari senyawa aktif yang terkandung dalam ekstrak daun teh hijau yang menyengat dari penguapan alat hit, apabila waktu pemaparan semakin lama maka semakin tinggi tingkat kematian nyamuk, karena aroma yang di hasilkan menyengat sehingga nyamuk akan mati satu persatu. Pendapat ini sejalan dengan penelitian Fadhillah (2013) yang berjudul Kemampuan Ektrak Daun Papaya (carica papaya) Dalam Mengendalikan Nyamuk Aedes aegypti mengemukakan bahwa pada pemaparan setiap waktu tingkat kematian nyamuk berbeda - beda dan pada setiap konsentrasi yang digunakan tingkat kematian nyamuk berbeda pula, pada konsentrasi $60 \%$ kematian nyamuk pada penelitian sebanyak 17 ekor dengan waktu pemaparan selama 240 menit. Jika dibandingkan dengan penelitian ini pada konsentrasi $60 \%$ lebih efektif karena kandungan senyawa aktif senyawa flavonoid yang banyak ditemukan sekitar 30\% - 40\%, senyawa Flavonoid berfungsi sebagai racun pernapasan.

Pada konsentrasi $80 \%$, Diperoleh rata-rata kematian yaitu pemaparan pada 15 menit semua nyamuk menepi kepinggir kurungan sehingga belum ada nyamuk yang mati, disebabkan karena waktu pemaparan yang relatif singkat. kemudian pada 30 menit kematian nyamuk sebanyak 1 ekor (4\%), kematian nyamuk dengan waktu yang cepat disebabkan karena kandungan senyawa aktif yang lebih tinggi sehingga aroma yang di uapkan lebih menyengat jika dibandingkan dengan konsentrasi $60 \%$. Setelah 45 menit diperoleh kematian nyamuk sebanyak 2 ekor (8\%) disebabkan karena nyamuk semakin terpapar dengan aroma senyawa aktif ekstrak daun teh hijau, yang bekerja merusak tubuh nyamuk sehingga nyamuk mati. Kemudian pada 60 menit kematian nyamuk meningkat sebanyak 3 ekor (12\%) kematian nyamuk yang semakin meningkat disebakan karena waktu terpaparnya nyamuk dengan aroma senyawa aktif relatif lama sehingga kematian nyamuk semakin meningkat, selanjutnya pada 75 menit diperoleh sebanyak 3 ekor (12\%) disebabkan karena nyamuk yang banyak menghirup aroma ekstrak daun teh hijau akan mati. Pada pemaparan 90 menit kematian nyamuk bertambah menjadi 4 ekor (16\%) hal ini disebabkan karena waktu terpaparnya nyamuk dengan aroma senyawa aktif yang lama sehingga kematian nyamuk semakin meningkat, kemudian pada 105 menit kematian nyamuk sebanyak 4 ekor (16\%) karena senyawa aktif yang menyengat yang telah merusak tubuh nyamuk sehingga nyamuk mati. dan pada 120 menit diperoleh kematian nyamuk sebanyak 5 ekor (20\%) hal 
Jurnal Sulolipu : Media Komunikasi Sivitas Akademika dan Masyarakat

Vol. 21 No.2 2021

e-issn : 2622-6960, p-issn : 0854-624X

ini disebabkan karena waktu terpaparnya nyamuk yang semakin lama dengan aroma senyawa aktif sehingga kematian nyamuk semakin meningkat. Kematian nyamuk ditandai setelah kurungan digerakkan, nyamuk dalam keadaan tidak mampu bergerak,, kondisi sama setelah alat hit keluarkan dari kurungan. Dari hasil pemaparan replikasi I, II dan III selama 120 menit pada konsentrasi $80 \%$. kematian ratarata nyamuk Aedes aegypti sebanyak 22 ekor $(88 \%)$.

Dapat disimpulkan bahwa Lethal Consentration 50 (LC_50) telah tercapai, artinya ekstrak daun teh hijau pada konsentrasi $80 \%$ mampu mematikan nyamuk Aedes aegypti karena telah memenuhi kriteria (LC_50) dimana kematian nyamuk melebihi $50 \%$ yaitu sebanyak $88 \%$. Hal ini disebabkan dosis yang diberikan lebih tinggi sehingga kandungan senyawa aktif pada konsentrasi $80 \%$ lebih banyak, kandungan senyawa aktif lebih menyengat sehingga jumlah kematian nyamuk lebih meningkat, hal tersebut menunjukkan bahwa dosis yang tinggi akan mempengaruhi jumlah kematian. Pendapat ini sejalan dengan Steven (2013) dengan judul penelitian Kemampuan Ekstrak Daun Pandan Wangi (pandanus amaryllifolius) Untuk Membunuh Nyamuk Aedes aegypti mengemukakan pendapat bahwa semakin tinggi konsentrasi perlakuan semakin banyak jumlah nyamuk Aedes aegypti yang mati.

Pada konsentrasi 100\%, Diperoleh rata-rata kematian yaitu pemaparan pada 15 menit semua nyamuk menepi kepinggir kurungan sehingga tidak terdapat kematian pada nyamuk yang disebabkan karena waktu pemaparan yang relatif singkat. Kemudian pada 30 menit sebanyak 2 ekor (8\%) \%), kematian nyamuk yang lebih awal dan lebih banyak disebabkan karena kandungan senyawa aktif ektrak daun teh yang lebih tinggi sehingga aroma yang di uapkan lebih menyengat jika dibandingkan dengan konsentrasi $60 \%$ dan $80 \%$. Setelah 45 menit diperoleh kematian nyamuk sebanyak 3 ekor $(12 \%)$ nyamuk semakin terpapar dengan aroma senyawa aktif ekstrak daun teh hijau, yang bekerja merusak tubuh nyamuk sehingga nyamuk mulai tergeletak , kemudian pada 60 menit diperoleh kematian nyamuk sebanyak 3 ekor (12\%) disebabkan karena nyamuk yang banyak menghirup aroma ekstrak daun teh hijau akan mati, selanjutnya pada 75 menit diperoleh sebanyak 4 ekor (16\%) disebabkan waktu terpaparnya nyamuk dengan aroma senyawa aktif yang lama sehingga kematian nyamuk semakin meningkat. Pada pemaparan 90 menit kematian nyamuk meningkat menjadi 4 ekor (16\%) disebabkan karena waktu terpaparnya nyamuk dengan aroma senyawa aktif yang lama, kemudian pada 105 menit bertambah menjadi 4 ekor (16\%) senyawa aktif yang berbau menyengat yang masuk dan telah merusak tubuh nyamuk sehingga nyamuk mati dan pada 120 menit diperoleh kematian nyamuk sebanyak 5 ekor $(20 \%)$, pada menit ke 120 menit seluruh nyamuk yang ada pada kurungan semua mati hal ini disebabkan karena konsentrasi $100 \%$ lebih menyengat karena kandungan senyawa aktif lebih tinggi dari konsentrasi $60 \%$ dan $80 \%$ sehingga mampu mematikan keseluruhan nyamuk. Kematian nyamuk ditandai setelah kurungan digerakkan, nyamuk dalam keadaan tidak mampu bergerak, kondisi yang sama setelah alat hit di keluarkan dari dalam kurungan. Dari hasil pemaparan replikasi I, II dan III selama 120 menit pada konsentrasi $100 \%$. kematian rata-rata nyamuk Aedes aegypti sebanyak 25 ekor (100\%).

Dapat disimpulkan bahwa Lethal Consentration 50 (LC_50) telah tercapai artinya ekstrak daun teh hijau pada konsentrasi $100 \%$ mampu mematikan nyamuk Aedes aegypti karena telah memenuhi kriteria (LC_50) dimana kematian nyamuk mencapai atau melebihi $50 \%$. Hal ini disebabkan karena konsentrasi 100\% mengandung ekstrak yang murni dari ekstrak daun teh hijau senyawa aktif yang terdapat pada ekstrak daun teh hijau lebih tinggi sehingga pada proses penguapan pada kotak percobaan akan lebih menyengat.

Pada kontrol tidak ditemukan nyamuk yang mati, sehingga hasil yang diperoleh dapat mencerminkan hasil yang sebenarnya dan adanya perbedaan antara perlakuan dan tanpa perlakuan, dengan jumlah kematian nyamuk yang berbeda setiap konsentrasi.

Hasil penelitian dapat disimpulkan bahwa pemaparan pada konsentrasi $60 \%$, $80 \%$ dan $100 \%$ ekstrak daun teh hijau telah mampu memenuhi Lethal Consentration 50 (LC_50),dari 3 perlakuan berbeda diperoleh hasil kematian yang berbeda, diperoleh persentase kematian nyamuk yang tertinggi pada konsentrasi $100 \%$ sebanyak 25 ekor $(100 \%)$, dan rata-rata persentase terendah terjadi pada konsentrasi $60 \%$ yaitu sebanyak 18 ekor (72\%). Hal tersebut menunjukan bahwa uji toksisitas sebuah senyawa 
Jurnal Sulolipu : Media Komunikasi Sivitas Akademika dan Masyarakat

Vol. 21 No.2 2021

e-issn : 2622-6960, p-issn : 0854-624X

tergantung pada dosis atau konsentrasi yang diberikan, semakin tinggi konsentrasi pada perlakuan maka semakin tinggi pula tingkat kematian. Tingkat kematian nyamuk disebabkan karena adanya perbedaan konsentrasi, hal ini disebabkan jumlah bahan aktif yang terdapat pada daun teh hijau yang dikandung. Semakin tinggi konsentrasi maka semakin banyak bahan aktif yang terkandung sehingga semakin besar bahan aktif yang diuapkan dengan metode elektrik (alat hit), Pendapat ini sejalan dengan penelitian yang dilakukan oleh Armayanti (2019) yang berjudul Efektivitas Ekstrak Daun Mengkudu Dengan Metode Spray Dalam Pengendalian Nyamuk Aedes Aegypti mengatakan bahwa apabila konsentrasi yang digunakan tinggi, maka tingkat kematian nyamuk semakin cepat dan jumlah yang banyak.

Penelitian yangtelah dilakukan sejalan pada Penelitian Amelinda,dkk (2018) tentang uji efektifitas ekstrak daun teh hijau (camelia sinensis) Terhadap kematian nyamuk Aedes aegypti, dengan konsentrasi $55 \%$, konsentrasi $65 \%$, Konsentrasi $75 \%$, konsentrasi $85 \%$ dan Konsentrasi 95\% yang paling efektif adalah pada konsentrasi $95 \%$. Hal ini membuktikan bahwa jumlah kematian nyamuk berbanding lurus dengan besarnya konsentrasi yang digunakan.

Dari hasil penelitian diatas jika dibandingkan dengan penelitian yang dilakukan oleh Amelinda,dkk (2018), maka dapat dilihat bahwa hasil yang didapatkan lebih efektif dengan adanya penambahan konsentrasi dan waktu pemaparan selama 2 jam (120 menit) sehingga mempengaruhi hasil yang di dapatkan, dengan tingkat kematian yang paling efektif adalah $100 \%$.

Kematian nyamuk disebabkan karena pada daun teh hijau terdapat kandungan senyawa aktif yaitu, senyawa flavonoid yang banyak ditemukan pada daun teh hijau sekitar 30\% - 40\%, senyawa Flavonoid berfungsi sebagai racun pernapasan sehingga saat nyamuk Aedes aegypti melakukan pernapasan, flavonoid akan masuk bersama udara (O2) melalui alat pernapasannya berupa spirakel yang terdapat dipermukaan tubuh nyamuk. Setelah melakukan pernapasan flavonoid akan menyerang bagian saraf pada beberapa organ vital serangga, sehingga timbul suatu perlemahan saraf, seperti syaraf pernapasan serta kerusakan pada bagian spirakel, hal tersebut akan mengakibatkan nyamuk tidak bisa bernafas dan akhirnya mati (Ambarwati, 2014), Pada senyawa saponin dapat mengganggu sistem pernapasan serangga yang dapat menimbulkan kelayuan pada saraf serta kerusakan pada spirakel hal ini dapat mengakibatkan serangga tidak mampu bernafas dan akhirnya mengalami kematian. Jika mengenai permukaan kulit serangga, mukosa kulit serangga tersebut akan rusak. Senyawa tanin akan mengerutkan dinding sel atau membran sel sehingga mengakibatkan permeabilitas sel sehingga tidak mampu melakukan aktivitas hidup dan pertumbuhannya terhambat dan dapat mengakibatkan mati (Budi,2014). Minyak atsiri merupakan senyawa metabolit sekunder yang tersusun dari campuran zat yang mudah menguap (volatil) karena terdapat dalam kelenjar minyak khusus didalam kantung minyak atau di dalam ruang antar sel dalam jaringan tanaman, dengan komposisi dan titik didih yang berbeda beda. dan bukan merupakan senyawa murni tetapi tersusun atas beberapa komponen yang mayoritas berasal dari golongan terpenoid. (Hasni,2020).

Adapun hasil Pengukuran suhu pada saat penelitian berlangsung pada tempat penelitian yang diukur diperoleh $30^{\circ} \mathrm{C}-$ $34^{\circ} \mathrm{C}$ suhu udara tersebut tidak mempengaruhi penelitian karena suhu yang terlalu tinggi atau terlalu rendah dapat mempengaruhi kelangsungan hidup nyamuk.Apabila suhu kurang dari $10^{\circ} \mathrm{C}$ atau lebih dari $40^{\circ} \mathrm{C}$ maka pertumbuhan nyamuk akan berhenti. (Herdianti.2017)

Hasil pengukuran kelembaban udara tempat penelitian yang diukur pada saat penelitian berlangsung yaitu $65 \%-67 \%$ kelembapan tersebut tidak menggangu hasil dari yang didapatkan, hal ini disebabkan kelembapan udara yang mendukung kehidupan nyamuk yaitu sekitar 70\% - 89\%. (Zulaika at all.2017)

\section{KESIMPULAN}

Setelah melakukan pengujian dan analisis hasil, ekstrak daun teh hijau dalam mematikan nyamuk Aedes aegypti dengan berbagai variasi konsentrasi, maka dapat ditarik kesimpulan sebagai berikut :

Pada Konsentrasi $60 \%$ mampu mematikan nyamuk Aedes aegypti dengan waktu pemaparan selama 2 jam, hasil presentase kematian yang didapatkan adalah $72 \%$. Pada konsentrasi $80 \%$ mampu mematikan nyamuk Aedes aegypti dengan waktu pemaparan selama 2 jam, hasil presentase kematian yang didapatkan 
Jurnal Sulolipu : Media Komunikasi Sivitas Akademika dan Masyarakat

Vol. 21 No.2 2021

e-issn : 2622-6960, p-issn : 0854-624X

adalah $88 \%$. Dan konsentrasi $100 \%$ mampu mematikan nyamuk Aedes aegypti dengan waktu pemaparan selama 2 jam, hasil presentase kematian yang didapatkan adalah $100 \%$.

\section{SARAN}

Bagi Masyarakat dapat mengendalikan nyamuk Aedes aegypti menggunakan insektisida alami yaitu ekstrak daun teh hijau, dan untuk peneliti selanjutnya, dapat menggunakan nyamuk selain nyamuk Aedes Aegypti dan dapat mencoba dalam mematikan jentik nyamuk.

\section{DAFTAR PUSTAKA}

Ambanrvati, at all. 2014. Ekstrak Daun Kembang Sepafu (Hib Iscus Rosa-Srnensis L.J: tehadap Moftalitas Larua Nyamuk Aedes aegypti L. Jember: KIP Universitas Jember. Diakses 7 Juni 2021

Amelinda, at al 2018. Uji Efektivitas Ekstrak Daun Teh Hijau (Camellia Sinensis) Terhadap Kematian Nyamuk Aedes aegypti. Analis Kesehatan Sains, 7(2), 644-674.

Armayanti.2019. Efektivitas Ekstrak Daun Mengkudu Dengan Metode Spray Dalam Pengenalian Nyamuk Aedes Aegypti.Makassar:Politeknik Kesehatan Makassar Jurusan Kesehatan Lingkungan(KTI tidak diterbitkan)

Aseptianova at al. 2017. Efektifitas Pemanfaatan Tanaman Sebagai Insektisida Elektrik Untuk Mengendalikan Nyamuk Penular Penyakit DBD, 3(2), 10-19.

Budi.2014. Skrining Fitokimia Enam Genotipe Teh.Jurnal Balai Penelitian Tanaman Industri dan Penyegar. J. TIDP 1(2), 63-68

Dinkes,2019. Selama Januari 2019, 8 orang Penderita DBD Meningkat di Sulsel (Online) (Selama Januari 2019, 8 Orang Penderita DBD Meninggal di Sulsel (kompas.com) diakses 20 desember 2020

Fadillah.2013. Kemampuan Ektrak Daun Papaya (Carica papaya) Dalam Mengendalikan Nyamuk Aedes aegypti. Makassar:Politeknik Kesehatan Makassar Jurusan Kesehatan Lingkungan(KTI tidak diterbitkan)

Hasni \& Rafidah.2020. Kemampuan Ekstrak Daun Beluntas (Pluchea Indica Linn) Dalam Mematikan Jentik Nyamuk Aedes Aegypti. Jurnal Sulolipu. Vol. 20 No.1

Herdianti.2017. Hubungan Suhu, Kelembaban dan Curah Hujan terhadap Keberadaan Jentik Nyamuk Aedes Aegypti Di RT 45 Kelurahan Kenali Besar. Jurnal Riset Informasi Kesehatan, Vol. 6, No. 1

Kemenkes RI,2020. Update data Demam Berdarah Dangue (Online) Kemenkes: Kasus DBD Januari Hingga Juli 2020 Capai Angka 71.633 - Health Liputan6.com, diakses 20 desember 2020

Sukohar. 2014. ( DBD ) Demam Berdaerah Dangue. Fakultas Kedokteran Universitas Lampung Demam Berdarah Dengue (DBD),2, 2.

Zulaika at all.2017. Efektivitas Berbagai Konsentrasi Ekstrak Daun Cengkeh (Syzygium Aromaticum, L.) Sebagai Repellent Terhadap Daya Hinggap Nyamuk Aedes Aegypti. Vol.38 No.3 Hal.1-62 
Jurnal Sulolipu : Media Komunikasi Sivitas Akademika dan Masyarakat

Vol. 21 No.2 2021

e-issn : 2622-6960, p-issn : 0854-624X

Tabel 1

Hasil Pemaparan Ekstrak Daun Teh Hijau (Camellia sinensis) Dalam Mem atikan Nyamuk Aedes aegypti pada Konsentrasi $60 \%$

\begin{tabular}{|c|c|c|c|c|c|c|c|}
\hline \multirow[t]{2}{*}{ No } & \multirow[t]{2}{*}{ Waktu (Menit) } & \multicolumn{4}{|c|}{$\begin{array}{l}\text { Jumlah Kematian Nyamuk } \\
\text { Setiap Replikasi }\end{array}$} & \multirow[t]{2}{*}{$\begin{array}{l}\text { Rata-Rata } \\
\text { Kematian }\end{array}$} & \multirow[t]{2}{*}{$\begin{array}{l}\text { \% Rata-Rata } \\
\text { Kematian }\end{array}$} \\
\hline & & Kontrol & I & II & III & & \\
\hline 1. & 15 menit & 0 & 0 & 0 & 0 & 0 & 0 \\
\hline 2. & 30 menit & 0 & 0 & 0 & 0 & 0 & 0 \\
\hline 3. & 45 menit & 0 & 2 & 1 & 2 & 2 & $8 \%$ \\
\hline 4. & 60 menit & 0 & 2 & 2 & 2 & 2 & $8 \%$ \\
\hline 5. & 75 menit & 0 & 2 & 3 & 3 & 3 & $12 \%$ \\
\hline 6. & 90 menit & 0 & 3 & 3 & 3 & 3 & $12 \%$ \\
\hline 7. & 105 menit & 0 & 4 & 5 & 4 & 4 & $16 \%$ \\
\hline 8. & 120 menit & 0 & 5 & 4 & 4 & 4 & $16 \%$ \\
\hline Tots & & 0 & 18 & 18 & 18 & 18 & $72 \%$ \\
\hline
\end{tabular}

Sumber : Data Primer 2021

Tabel 2

Hasil Pemaparan Ekstrak Daun Teh Hijau (Camellia sinensis) Dalam Mematikan Nyamuk Aedes aegypti pada Konsentrasi $\mathbf{8 0 \%}$

\begin{tabular}{llllllll}
\hline No & Waktu (Menit) & \multicolumn{2}{l}{$\begin{array}{l}\text { Jumlah Kematian Nyamuk Setiap } \\
\text { Replikasi }\end{array}$} & $\begin{array}{l}\text { Rata-Rata } \\
\text { Kematian }\end{array}$ & $\begin{array}{l}\text { \% Rata-Rata } \\
\text { Kematian }\end{array}$ \\
\cline { 3 - 6 } & Kontrol & I & II & III & & \\
\hline 1. & 15 menit & 0 & 0 & 0 & 0 & 0 & 0 \\
\hline 2. & 30 menit & 0 & 1 & 1 & 2 & 1 & $4 \%$ \\
\hline 3. & 45 menit & 0 & 2 & 3 & 2 & 2 & $8 \%$ \\
\hline 4. & 60 menit & 0 & 3 & 3 & 4 & 3 & $12 \%$ \\
\hline 5. & 75 menit & 0 & 3 & 3 & 3 & 3 & $12 \%$ \\
\hline 6. & 90 menit & 0 & 4 & 4 & 2 & 4 & $16 \%$ \\
\hline 7. & 105 menit & 0 & 4 & 4 & 3 & 4 & $16 \%$ \\
\hline 8. & 120 menit & 0 & 5 & 4 & 5 & 5 & $20 \%$ \\
\hline Total & & 0 & 22 & 22 & 21 & 22 & $88 \%$
\end{tabular}

Sumber : Data Primer 2021 
Jurnal Sulolipu : Media Komunikasi Sivitas Akademika dan Masyarakat

Vol. 21 No.2 2021

e-issn : 2622-6960, p-issn : 0854-624X

Tabel 3

Hasil Pemaparan Ekstrak Daun Teh Hijau (Camellia sinensis) Dalam Mematikan Nyamuk Aedes aegypti pada Konsentrasi $100 \%$

\begin{tabular}{llllllll}
\hline No & $\begin{array}{l}\text { Waktu } \\
\text { (Menit) }\end{array}$ & $\begin{array}{l}\text { Jumlah Kematian Nyamuk Setiap } \\
\text { Replikasi }\end{array}$ & $\begin{array}{l}\text { Rata-Rata } \\
\text { Kematian }\end{array}$ & $\begin{array}{l}\text { \% Rata-Rata } \\
\text { Kematian }\end{array}$ \\
\cline { 3 - 6 } Kontrol & I & II & III & & 0 \\
\hline 1. & 15 menit & 0 & 0 & 0 & 0 & 0 & $8 \%$ \\
\hline 3. & 30 menit & 0 & 2 & 3 & 2 & 2 & $12 \%$ \\
\hline 4. & 65 menit & 0 & 2 & 3 & 3 & 3 & $12 \%$ \\
\hline 5. & 75 menit & 0 & 3 & 4 & 3 & 3 & $16 \%$ \\
\hline 6. & 90 menit & 0 & 4 & 3 & 4 & 4 & $16 \%$ \\
\hline 7. & 105 menit & 0 & 4 & 4 & 3 & 4 & $16 \%$ \\
\hline 8. & 120 menit & 0 & 4 & 4 & 5 & 4 & $20 \%$ \\
\hline Total & & 0 & 5 & 4 & 5 & 5 & $100 \%$
\end{tabular}

Sumber : Data Primer 2021

Tabel 4

Gabungan Hasil Pemaparan Ekstrak Daun Teh Hijau (Camellia sinensis) Dalam Mematikan Nyamuk Aedes aegypti pada Konsentrasi $60 \%$, $80 \%$ dan $100 \%$

\begin{tabular}{|c|c|c|c|c|c|c|c|}
\hline \multirow[t]{2}{*}{ No } & \multirow[t]{2}{*}{ Konsentrasi } & \multirow[t]{2}{*}{$\begin{array}{l}\text { Jumlah } \\
\text { Nyamuk pada } \\
\text { Uji Perlakuan }\end{array}$} & \multicolumn{3}{|c|}{$\begin{array}{l}\text { Jumlah Kematian } \\
\text { Nyamuk Setiap } \\
\text { Replikasi }\end{array}$} & \multirow[t]{2}{*}{$\begin{array}{l}\text { Rata-rata } \\
\text { Kematian }\end{array}$} & \multirow[t]{2}{*}{$\begin{array}{l}\text { \% } \\
\text { Rata-rata } \\
\text { Kematian }\end{array}$} \\
\hline & & & I & II & III & & \\
\hline 1. & Kontrol & 25 & 0 & 0 & 0 & 0 & 0 \\
\hline 2. & $\begin{array}{l}\text { Konsentrasi } \\
60 \%\end{array}$ & 25 & 18 & 18 & 18 & 18 & $72 \%$ \\
\hline 3. & $\begin{array}{l}\text { Konsentrasi } \\
80 \%\end{array}$ & 25 & 22 & 22 & 21 & 22 & $88 \%$ \\
\hline 4. & $\begin{array}{l}\text { Konsentrasi } \\
100 \%\end{array}$ & 25 & 24 & 25 & 25 & 25 & $100 \%$ \\
\hline
\end{tabular}

Sumber : Data Primer 2021 